\title{
Experimental Analysis of HC Emission Behavior from a Lean Burn LPG Engine during Transient Operating Conditions
}

\author{
Zhang Zhongbo ${ }^{1}$, Li Lifu ${ }^{1}$ and Ou Jiajie ${ }^{2}$ \\ ${ }^{1}$ School of Mechanical and Automotive Engineering, South China University of Technology, Guangzhou, 510641, China \\ ${ }^{2}$ Institute of Mechanical and Electrical Engineering, Guangzhou University, Guangzhou, 510006, China
}

\begin{abstract}
Based on engine bench test system, the HC emission behavior of a lean burn LPG engine during constant speed and changing (increasing an d decreasing) torque transient conditions was investigated. Results show that HC is significantly deteriorated under the experimental operating conditions. HC concentration value is higher than the steady-state value by $2.3 \%$ and $14.2 \%$, respectively. The response of the actual torque lags behind the desired torque by $2.047 \mathrm{~s}$ and $2.109 \mathrm{~s}$, respectively, and leads to the actual speed deviates from the desired value by $4.5 \%$ and $3.7 \%$. The deviation of the actual speed causes the fluctuations of IAA, which is the key reason for the deterioration of HC under increasing torque operation. The control of fuel valve cannot meet the demand of the actual LPG mass during the transient operating conditions, leads to the actual LPG mass value deviate from the target value by $4.7 \%$ and $8.8 \%$, respectively. And this is also the main responsibility for the actual AFR deviate from the target value by $5.1 \%$ and $8.2 \%$, respectively. During the decreasing torque operation, caused by the deviation of the actual AFR, the mixture is too rich, which results in the deterioration of $\mathrm{HC}$.
\end{abstract}

\section{Introduction}

LPG (Liquefied Petroleum Gas) has been widely used as an alternative fuel for vehicle engine due to its good fuel properties and environmental protection[1]. However, with gradually stricter emission regulations, to further reduce the emissions of $\mathrm{LPG}$ engine is a vital issue for its manufacturers.

Scholars have done many researches on the subject of LPG engine emissions[2-5]. However, the researches mainly have focused on the steady-state emissions behavior of LPG engine, with much less attention paid to the emissions behavior under transient operating conditions, especially acceleration and deceleration. As we all know, the vehicle engines mainly operate under transient conditions during daily driving. Under the transient conditions, the rapid change of the parameters (such as fuelling and air-supply) and the unstable combustion boundaries (such as thermodynamic state and in-cylinder mixture state) can easily cause the deterioration of combustion in-cylinder and lead to the deterioration of emissions eventually [6].

$\mathrm{HC}$ (Hydrocarbon) is one of the main emissions of LPG engine and is mainly produced fro $m$ the unburned or incomplete burned LPG. Due to its vital contribution for the formation of photochemical smog, most countries and regions put forward strict limits on it.

To investigate the $\mathrm{HC}$ behavior of LPG engine during the transient conditions, this study takes a premixed spark ignition lean burn LPG engine as its research object.
Based on engine bench test system, the $\mathrm{HC}$ behavior of LPG engine under constant speed and changing torque transient conditions was experimented. Also, together with the formation mechanism of $\mathrm{HC}$, the related factors were analyzed.

\section{Experimental system and conditions}

\subsection{Experimental system and principle}

The engine used in this study is an YC6112ZLQE in-line 6-cylinder, 4-stroke, turbocharged, after-cooled, closed loop control of AFR (air-fuel ratio), spark ignition, premixed lean burn LPG engine, and is widely used to power city buses. Its basic technical data are given in Table 1.

Table 1. LPG engine specifications

\begin{tabular}{|c|c|}
\hline Item & Parameter \\
\hline Compression ratio & 8.5 \\
\hline Rated power $(\mathrm{kW})$ & 162 \\
\hline Rated speed $\left(\mathrm{r} \cdot \mathrm{min}^{-1}\right)$ & 2300 \\
\hline Maximum torque $(\mathrm{N} \cdot \mathrm{m})$ & 800 \\
\hline $\begin{array}{c}\text { Maximum torque } \\
\text { speed }\left(\mathrm{r} \cdot \mathrm{min}^{-1}\right)\end{array}$ & $1300 \sim 1400$ \\
\hline Idling Speed $\left(\mathrm{r} \cdot \mathrm{min}^{-1}\right)$ & $650 \pm 25$ \\
\hline $\begin{array}{c}\text { Exhaust temperature after the } \\
\text { turbine }\left({ }^{\circ} \mathrm{C}\right)\end{array}$ & $\leq 640$ \\
\hline
\end{tabular}


The principle of LPG engine bench test system is illustrated in Fig.1. The main instrumentations include: Xiangyi GW 250 eddy current dynamometer, Xiangyi FC2012 MCI(Measurement and Control Instrument), Xiangyi FC2110 drive, Guang zhou Fuli FLB-501 exhaust analyzer and Advantech 610MB IPC (Industrial Personal Computer). With IPC used as the carrier, engine experimental management software based on Lab VIEW is developed.

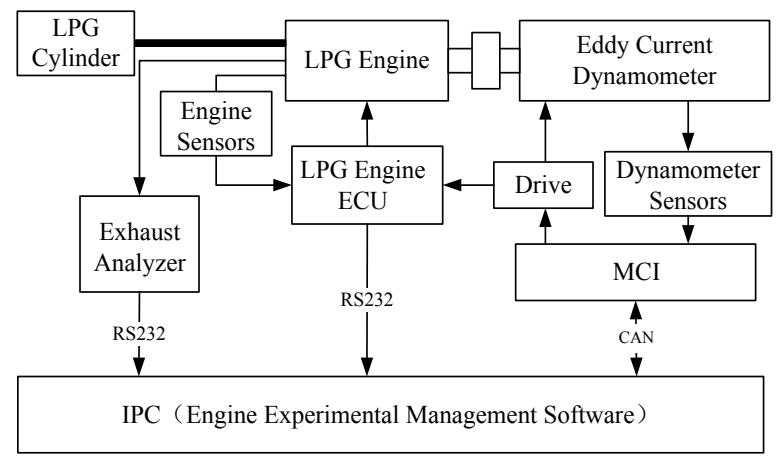

Figure 1. Schematic diagram of LPG engine bench test system

During the test, LPG engine experimental operations (desired speed and torque) are preset in IPC who controls the drive. The drive sends electronic accelerator pedal signals to LPG engine ECU (Electronic Control Unit) to control the brake power while changes the excitation current to adjust the brake torque of eddy current dynamometer. Collecting the actual engine operations (actual speed and torque) in real time, the dynamometer sensors continuously feed it back to MCI who adjusts the engine operations again, so that LPG engine can be operated following the preset conditions. Experimental data are recorded in real-time by IPC, include: pressure before throttle, MAP (manifold absolute pressure), fuel valve opening, AFR, IAA (ignition advance angle), engine torque, speed and $\mathrm{HC}$ emission.

\subsection{Experimental operating conditions}

The engine transient operating conditions main ly include: starting, constant speed and changing torque, constant torque and changing speed, etc[7]. However, constant speed and changing torque operation is in a large proportion in all types of test cycle, e.g. the ratio that this condition in the European Transient Cycle is 61.13\% [8]. As a result, constant speed and changing torque operation is usually used as a typical transient condition [9] and is widely used in engine transient performance experiments.

Therefore, the transient $\mathrm{HC}$ behavior of LPG engine was experimented under constant speed and changing torque operation in this test. According to the characteristic of this LPG engine, the transient operation was based on constant speed $1100 \mathrm{r} \bullet \mathrm{min}^{-1}$ and changing torque from $110 \mathrm{~N} \cdot \mathrm{m}$ to $320 \mathrm{~N} \cdot \mathrm{m}$ over a $3 \mathrm{~s}$ transition time. The detailed test operation is shown in Fig.2. And the constant speed and changing torque condition was divided into two operations: increasing torque operation and decreasing torque condition, respectively.

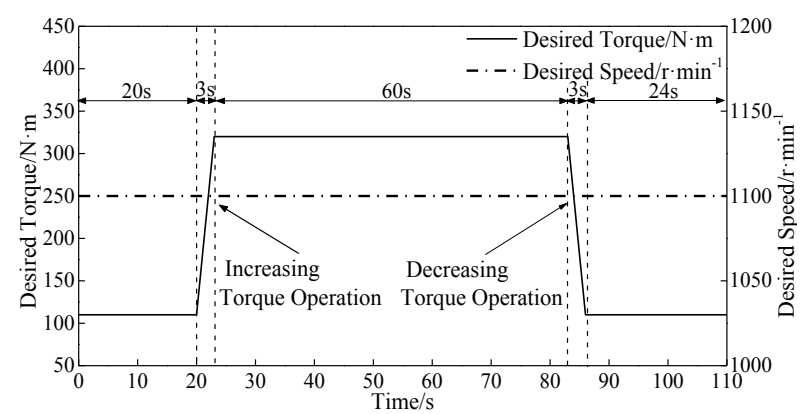

Figure 2. Experimental operation of LPG engine

\section{Experimental results and analysis}

\subsection{Transient $\mathrm{HC}$ emission behavior}

Under the experimental conditions, the respond of $\mathrm{HC}$ concentration (volume concentration) in the exhaust is shown in Fig.3.

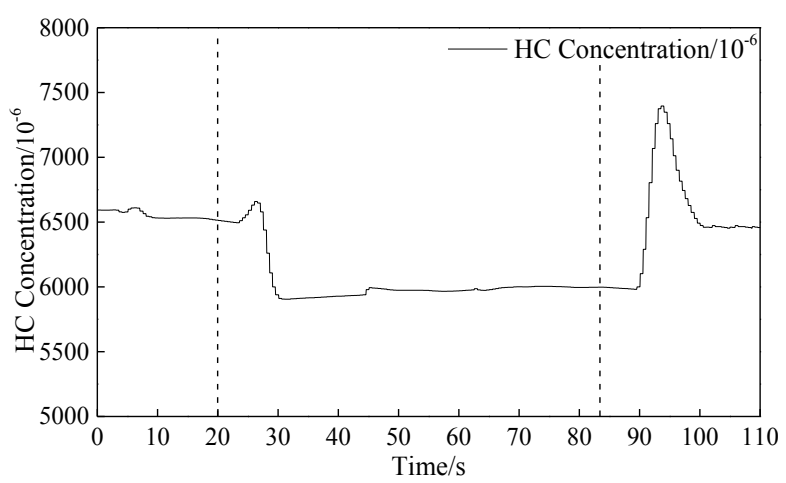

Figure 3. The respond of $\mathrm{HC}$ concentration in the exhaust

Fig.3 presents that during the increasing torque operation, HC concentration increases from $6511 \times 10^{-6}$ $(23.672 \mathrm{~s})$ to a peak of $6659 \times 10^{-6}(26.172 \mathrm{~s})$ and subsequently decreases to $5906 \times 10^{-6}(30.625 \mathrm{~s})$ with a small spike formed, and it is higher than its steady-state value by $2.3 \%(26.172 \mathrm{~s})$, indicates that $\mathrm{HC}$ is slightly deteriorated. During the decreasing torque operation, HC concentration increases from $6000 \times 10^{-6}(90.062 \mathrm{~s})$ to a maximum of $7396 \times 10^{-6}(94.015 \mathrm{~s})$ and then decreases to $6474 \times 10^{-6}(100.078 \mathrm{~s})$ and forms a larger peak, and it is higher than its steady-state value by $14.2 \%(94.015 \mathrm{~s})$, shows that $\mathrm{HC}$ is seriously deteriorated.

\subsection{Analysis of actual experimental conditions}

According to the engine principle, AFR and temperature in-cylinder is different among various operating conditions, thus the emissions are different [10]. For the transient $\mathrm{HC}$ behavior test of LPG engine, the experimental system changes the engine brake power by controlling electronic accelerator pedal signal, and the load of engine is changed by controlling the excitation current of eddy current dynamometer (that is to say, to change the engine brake torque). However, due to the slow response of dynamometer, the engine brake torque 
will lag behind. According to the definition of engine brake power

$$
P=M n
$$

where $M$ is the brake torque and $n$ is the rotational speed. When the brake power of LPG engine changes, the lag of brake torque will cause the fluctuations of engine speed. Therefore, the actual conditions of engine are difficult to operate in accordance with the experimental conditions. For this reason, the influence of actual experimental conditions must be taken into account in the analysis of HC behavior of LPG engine under transient operating conditions. The respond of LPG engine torque and rotational speed under experimental operations is given in Fig.4 and Fig.5, respectively.

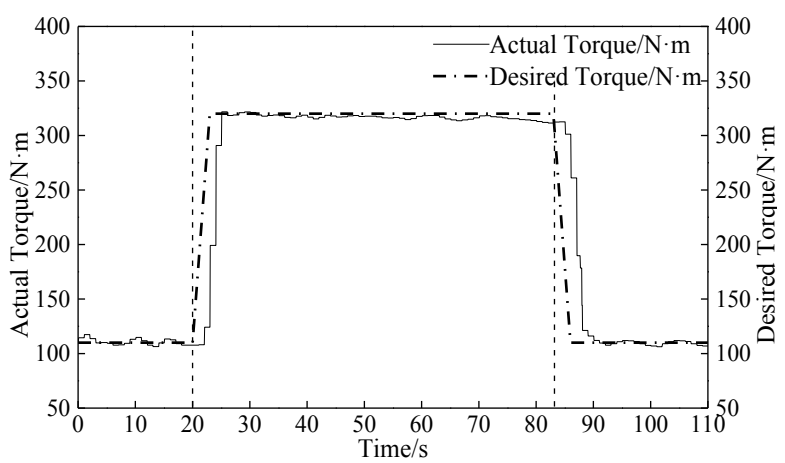

Figure 4. The respond of torque

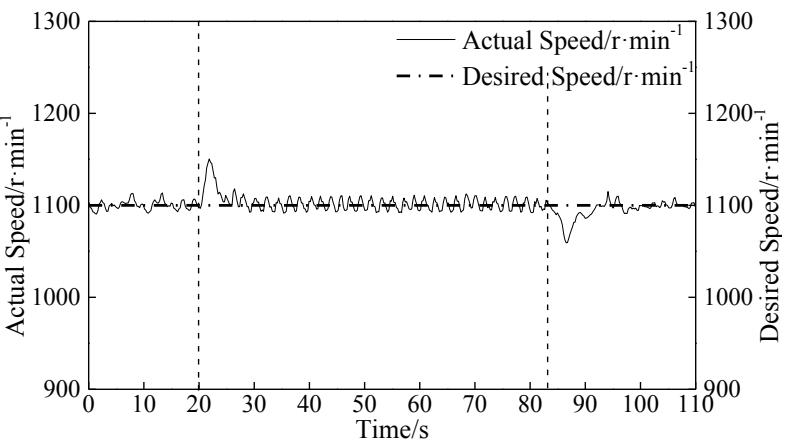

Figure 5. The respond of speed

Fig. 4 presents the respond of the actual torque lags behind the desired torque by $2.047 \mathrm{~s}$ and $2.109 \mathrm{~s}$, respectively. Fig.5 indicates, due to the lags of actual torque, the actual speed deviates from the desired speed by $4.5 \%(21.843 \mathrm{~s})$ and $3.7 \%(86.531 \mathrm{~s})$, respectively.

\subsection{Analysis of control parameters}

According to the formation mechanis ms of engine emissions, AFR and IAA is the main control parameter that affects the generation of spark ignition engine emis sions [10].

As shown in Fig.6 and Fig.7, the respond of AFR and IAA under experimental conditions is given, respectively. Fig. 6 presents that the target AFR is stable without obvious fluctuations under the experimental conditions. However, the actual AFR fluctuates greatly and deviates from the target AFR by $5.1 \%(22.765 \mathrm{~s})$ and $8.2 \%$ (87.218s), respectively. Fig.7 shows that the IAA also fluctuates greatly during the experimental conditions.

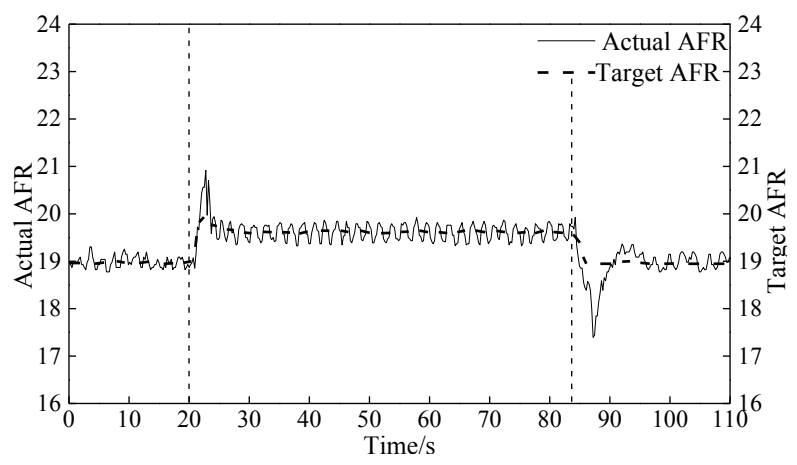

Figure 6. The respond of AFR

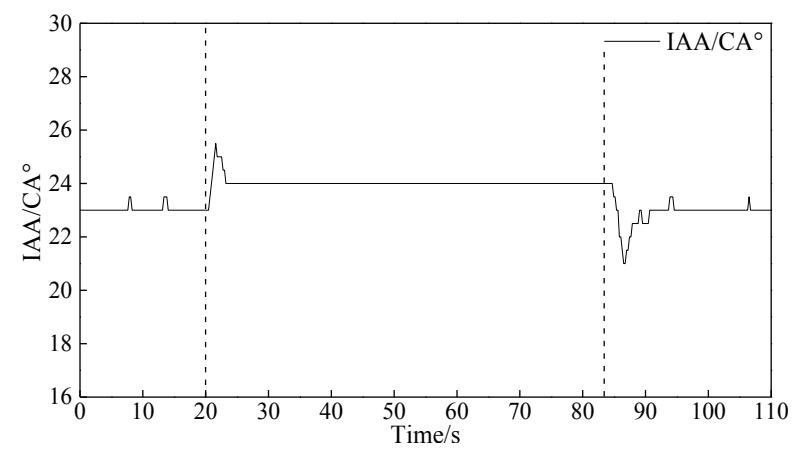

Figure 7. The respond of IAA

(1) Analys is of AFR

According to the basic principle of premixed mixture formation of LPG engine, as shown in Fig. 8, with regard to the respond of the actual AFR under the experimental conditions, AFR is defined by

$$
\alpha_{\mathrm{AFR}}=\frac{m_{\mathrm{air}}}{m_{\mathrm{LPG}}}
$$

where $m_{\text {air }}$ is the air inflow and $m_{\mathrm{LPG}}$ is the LPG mass.

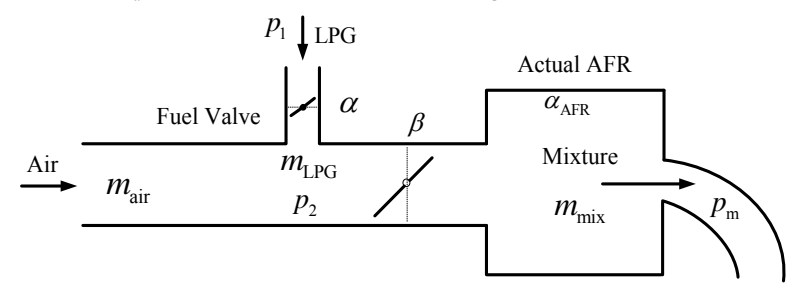

Figure 8. Schematic diagram of the premixed mixture formation of LPG engine

The speed-density equation is usually used to calculate the air inflow

$$
m_{\text {air }}=\left(P_{\mathrm{m}} /\left(R T_{\mathrm{m}}\right)\right) N \cdot n \cdot V_{\mathrm{h}} \eta_{\mathrm{v}}
$$

where $P_{\mathrm{m}}$ is the MAP; $R$ is the gas constant; $T_{\mathrm{m}}$ is the manifold air temperature(MAT); $N$ is the number of engine cylinders; $V_{\mathrm{h}}$ is the displacement and $\eta_{\mathrm{v}}$ is the volumetric efficiency.

For the Eq. (3), $V_{\mathrm{h}}$ is fixed, $N$ is 6 , the experimental data of $n$ is shown in Fig. 5 and the respond of MAP and 
MAT during the experimental conditions is given in Fig. 9 and Fig. 10, respectively.

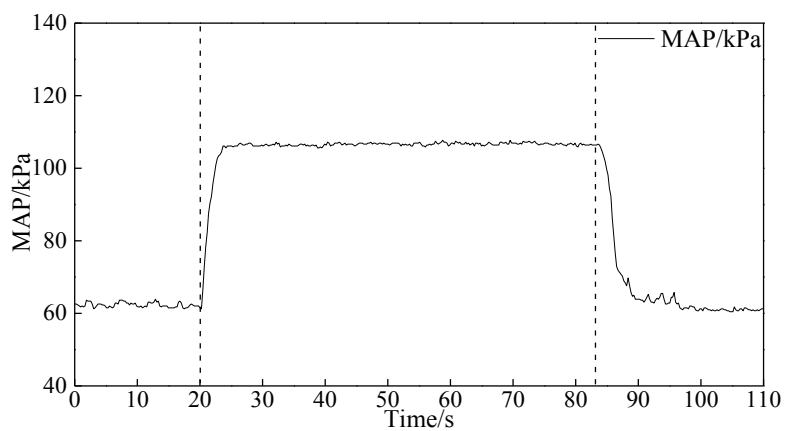

Figure 9. The respond of MAP

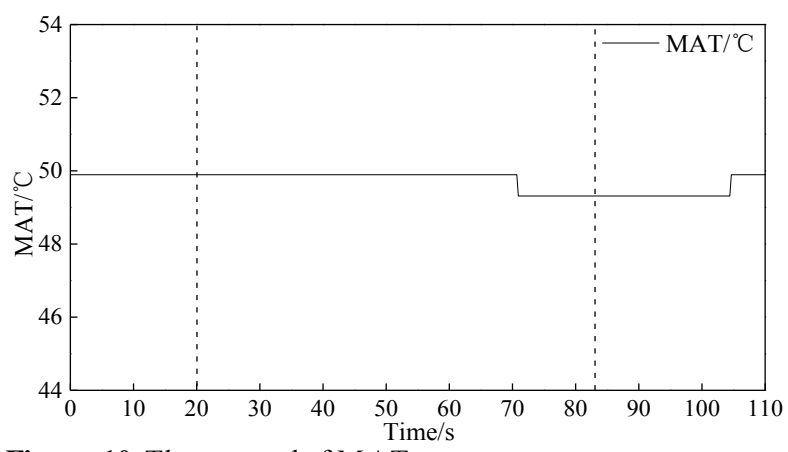

Figure 10. The respond of MAT

Fig.9 presents that the transition of the MAP during the experimental conditions is relatively stable without obviously fluctuations. It is shown in Fig.10, under the experimental operations, the variation of MAT is very small, only $0.7^{\circ} \mathrm{C}$.

For the volumetric efficiency, it can be calculated by the relation [11]

$$
\eta_{\mathrm{v}}=\frac{T_{0}}{P_{0}} \cdot \frac{\varepsilon}{\varepsilon-1} \cdot\left(\frac{P_{\mathrm{a}}}{T_{\mathrm{a}}}-\frac{P_{0}}{T_{0}}\right)
$$

where $T_{0}$ is the atmospheric temperature; $P_{0}$ is the atmospheric pressure; $\varepsilon$ is the compression ratio; $P_{\mathrm{a}}$ and $T_{\mathrm{a}}$ is the pressure and temperature of the mixture at the end of intake and is approximate equal to MAP and MAT, respectively.

Therefore, with Eqs.(3), (4) and the experimental data of MAP (Fig.9), MAT (Fig.10) and rotational speed (Fig.5), the respond of air inflow during the experimental conditions is calculated, which is given in Fig.11.

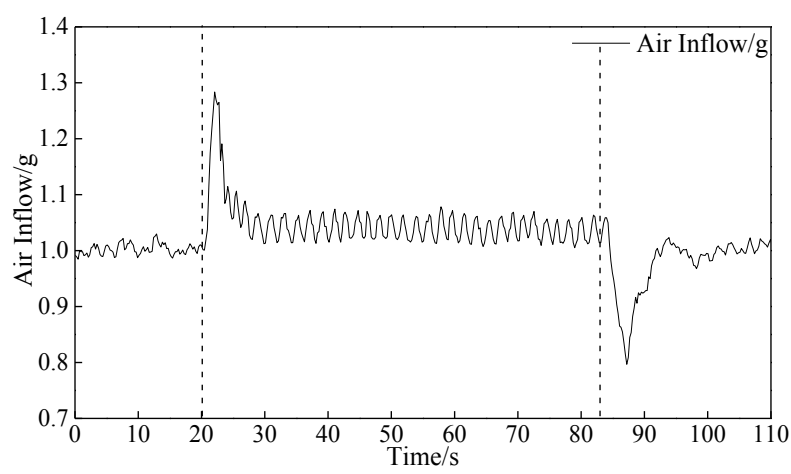

Figure 11. The respond of air inflow
Fig. 11 indicates that, with the increase of MAP, air inflow increases rapidly during the increasing torque condition. However, the increase of the speed further results in the increase of air inflow, which leads to the air inflow forms a large peak. Under the decreasing torque condition, the respond of MAP and speed is opposite to that during the increasing torque condition, which leads to the air inflow forms a large valley. Therefore, the fluctuations of engine speed (Fig.5) lead to the fluctuations of air inflow during the actual experimental conditions.

For the LPG mass, based on the calculation of air inflow and the determining of the target AFR by look-up table, ECU calculates the LPG mass under the current operating condition.

Therefore, by Eq.(2) and the experimental data of AFR (Fig.6) and air inflow(Fig.11), the respond of the actual and target LPG mass during the experimental operations is calculated, as shown in Fig.12.

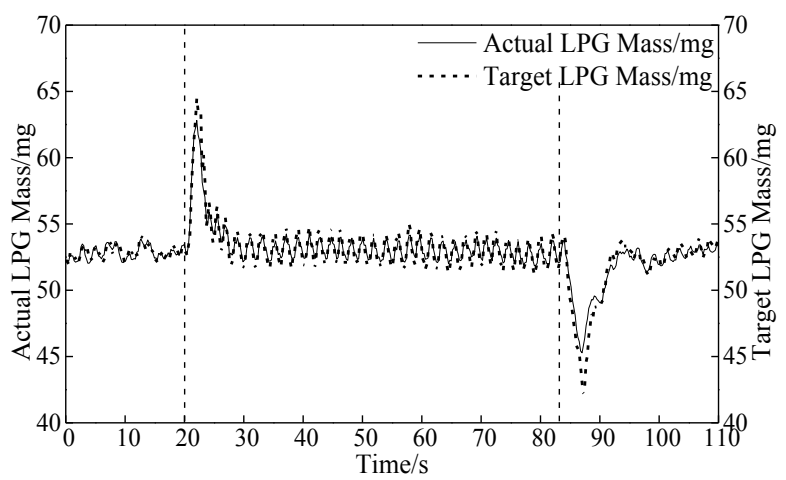

Figure 12. The respond of LPG mass

Fig. 12 presents, under the steady-state operations, the deviation from actual LPG mass to target value is small and is less than $1.85 \%$. However, during the transient operations, the deviation is much larger. Under the increasing torque condition, the actual LPG mass is smaller than the target value, and the maximal deviation is $4.7 \%(22.765 \mathrm{~s})$. During the decreasing torque condition, the actual LPG mass is much larger than the target one, and the maximal deviation is $8.8 \%(87.218 \mathrm{~s})$.

For the respond of LPG mass, according to the basic principle of premixed mixture formation of LPG engine in Fig.8, the LPG mass can be expressed by

$$
m_{\mathrm{LPG}}=C_{\mathrm{v}} A_{\mathrm{v}} \psi \frac{P_{1}^{2}}{P_{2} \sqrt{R T_{\mathrm{v}}}}
$$

where $T_{\mathrm{v}}$ is the LPG temperature; $P_{1}$ is the upstream pressure of the fuel valve; $P_{2}$ is the downstream pressure of the fuel valve that is equal to the pressure before throttle; $C_{\mathrm{v}}$ is the flow coefficient of the fuel valve which is related to the physical behavior of LPG and the difference of fuel valve upstream/downstream pressure, and can be calculated by the experimental method and the empirical equation Eq.(6)

$$
C_{\mathrm{v}}=a_{1}+a_{2} \alpha+a_{3} \alpha^{2}
$$


where $\alpha$ is the fuel valve opening; $a_{1}, a_{2}$ and $a_{3}$ is the coefficient can be acquired through experiment.

$A_{\mathrm{v}}$ is the effective cross-sectional area of the fuel valve and is a function of fuel valve opening, its expression is

$$
A_{\mathrm{v}}=\frac{\pi d^{2}}{4}\left(1-\cos ^{2} \alpha\right)
$$

where $d$ is the fuel valve diameter.

$\psi$ is the flow function that is related to the difference of the fuel valve upstream/downstream pressure, and its expression is

$$
\psi\left(\frac{P_{1}}{P_{2}}\right)=\left\{\begin{array}{cl}
\sqrt{\gamma\left[\frac{2}{\gamma+1}\right]^{\frac{\gamma+1}{\gamma-1}}} & \frac{P_{2}}{P_{1}} \leq\left[\frac{2}{\gamma+1}\right]^{\frac{\gamma}{\gamma-1}} \\
\left.\left(\frac{P_{2}(t)}{P_{1}(t)}\right)^{\frac{1}{\gamma}} \sqrt{\frac{2 \gamma}{\gamma-1}\left[1-\left(\frac{P_{2}}{P_{1}}\right)^{\frac{\gamma-1}{\gamma}}\right.}\right] & \frac{P_{2}}{P_{1}}>\left[\frac{2}{\gamma+1}\right]^{\frac{\gamma}{\gamma-1}}
\end{array}\right.
$$

where $\gamma$ is the specific heat ratio of LPG.

Therefore, accord ing to Eqs.(5) (8), the LPG mass is a function of $\alpha, T_{\mathrm{v}}, d, P_{1}, P_{2}$ and $\gamma$, i.e.

$$
m_{\mathrm{LPG}}=f\left(\alpha, T_{\mathrm{v}}, d, P_{1}, P_{2}, \gamma\right)
$$

However, in Eqs. (9) $d$ and $\gamma$ is constant, and due to the regulator, $T_{\mathrm{v}}$ and $P_{1}$ changed slightly can be seen as constant, so $m_{\mathrm{LPG}}$ is mainly affected by $\alpha$ and $P_{2}$, i.e.:

$$
m_{\mathrm{LPG}}=f\left(\alpha, P_{2}\right)
$$

The respond of fuel valve opening and pressure before throttle during the experimental operations is shown in Fig.13 and Fig.14, respectively.

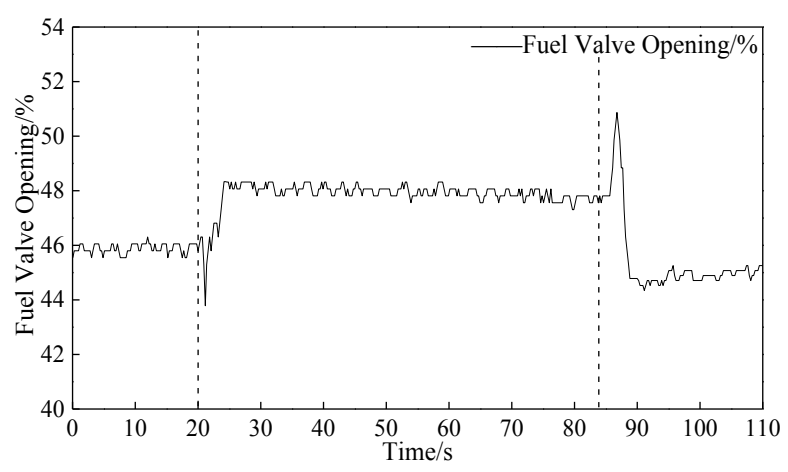

Figure 13. The respond of fuel valve opening

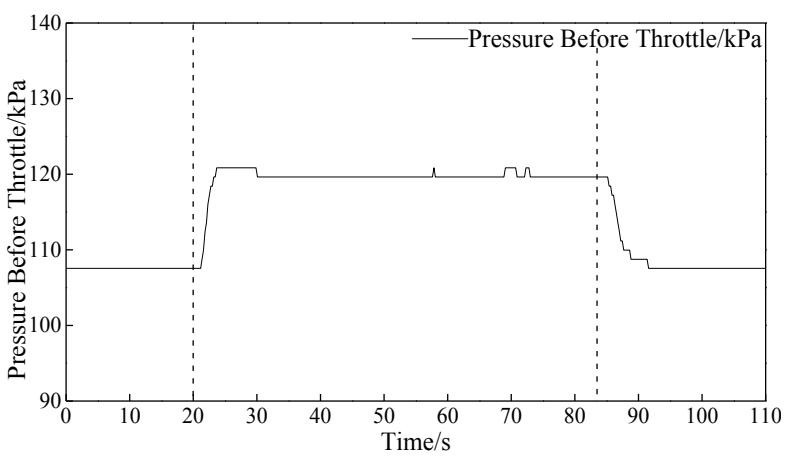

Figure 14. The respond of pressure before throttle
Fig. 13 shows that the fuel valve opening under the experimental operations fluctuates obviously. Fig.14 presents that the pressure before throttle under experimental operations has a smooth transition without noted fluctuations. According to the principle of LPG engine control system, fuel valve is the actuator of LPG engine control system. Therefore, the control of fuel valve cannot meet the needs of the actual LPG mass is the reason for the actual LPG mass deviation from the target value under transient operating conditions.

Hence, by the Eq.(2) and the analysis of the respond of air inflow and LPG mass under experimental condition, the control of fuel valve cannot meet the demand of actual LPG mass is the root cause of the LPG engine actual AFR deviates from the target value.

(2) Analysis of IAA

For the respond of IAA during the experimental conditions, by the control principle of the engine IAA, during the working process of engine, according to the MAP and the speed, the basic spark angle is obtained by look-up table and interpolation method. Based on the basic spark angle, the actual spark angle is obtained by a series of amendment. Therefore, the respond of IAA is mainly affected by MAP and speed.

According to the respond of speed (Fig.5), MAP (Fig.9) and IAA (Fig.7), during the increasing torque condition, with the increase of MAP, the IAA increases rapidly. However, the fluctuations of engine speed (increased first and then decreased) lead to the decrease of IAA after a further increase. Under the decreasing torque operation, the respond of the influencing factors of IAA are opposite to that during the increasing torque condition, IAA increases after a rapid decrease.

\subsection{Analysis of transient HC emission behavior}

For LPG engines, $\mathrm{HC}$ is the main product of incomplete combusted of LPG. The formation reaction of $\mathrm{HC}$ is complex in-cylinder and influenced by AFR and IAA obviously [10]. If the AFR of mixture is too small, LPG cannot be fully burned, which results in the increase of HC. The increase of AFR is beneficial to the complete combustion of LPG to reduce HC. However, a larger AFR will lead to the deterioration of combustion incylinder and even result in the phenomenon of misfire, which cause the increase of HC finally. Reducing the IAA is a favourable way to increase the temperature of engine exhaust, so that $\mathrm{HC}$ can be oxidized in exhaust systemand reduced consequently.

With the respond of HC (Fig.3), AFR (Fig.6) and IAA (Fig.7), during the increasing torque condition, the rapid increase of the actual AFR is beneficial to the complete combustion of LPG, which helps out with lighter HC concentration. Although the mixture concentration in this process is too thin, it can still be stable burn [12], so the dilution of mixture do not lead to the deterioration of $\mathrm{HC}$. However, whilst the IAA increases rapidly, which leads to the short of after combustion period and the decrease of exhaust temperature, weakens the oxidization of $\mathrm{HC}$ in exhaust stroke and exhaust system, results in the increase of HC eventually. Therefore, a small HC concentration 
peak is formed during the process. During the decreasing torque condition, the actual AFR decreases rapidly, and results in the unburned partial LPG. At the same time, the excessive rich of the mixture in this process further leads to the increase of the proportion of incomplete burned LPG. Therefore, $\mathrm{HC}$ concentration increases rapidly. Although the reduction of IAA is beneficial to reduce $\mathrm{HC}$, AFR is the dominant factors of $\mathrm{HC}$ form in this whole process, so a large $\mathrm{HC}$ concentration peak is formed.

\section{Conclusions}

To study HC emission behaviour of LPG engine during the transient conditions, based on engine bench test system, under constant speed and changing (increasing and decreasing) torque transient conditions, a lean burn LPG engine was tested and analysed.

(1)Under the experimental conditions, $\mathrm{HC}$ is significantly deteriorated. HC concentration value is higher than the steady-state value by $2.3 \%$ and $14.2 \%$, respectively.

(2)The respond of the actual torque lags behind the desired value by $2.047 \mathrm{~s}$ and $2.109 \mathrm{~s}$, respectively, leads to the actual speed deviates from the desired value with $4.5 \%$ and $3.7 \%$.

(3)The deviation of the actual speed causes the fluctuations of IAA, which is the key reason for the deterioration of $\mathrm{HC}$ under the increasing torque operation.

(4)During the experimental conditions, the control of fuel valve cannot meet the demand of actual LPG mass leads to the actual LPG mass value deviates from the target value by $4.7 \%$ and $8.8 \%$, respectively, and this is also the main responsibility for the actual AFR deviates from the target value (the deviation is $5.1 \%$ and $8.2 \%$, respectively).

(5)During the decreasing torque operation, caused by the deviation of actual AFR, the mixture is too rich, which results in the deterioration of $\mathrm{HC}$, eventually.

In order to decrease $\mathrm{HC}$ emission of LPG engine under transient operating conditions, new control methods of fuel valve and IAA need to be studied in the future.

\section{Acknowledgements}

This project is supported by National Natural Science Foundation of China (Grant No. 51605104).

\section{References}

1. Mitukiewicz G, Dychto R, Leyko J. Relationship between LPG fuel and gasoline injection duration for gasoline direct injection engines[J]. Fue1, 2015, 153: 526-534.

2. Erkus Baris, Karamangil M. Ihsan, Surmen Ali. Enhancing the heavy load performance of a gasoline engine converted for LPG use by modify ing the ignition timings[J]. Applied Thermal Engineering, 2015, 85: 188-194.

3. Oh Seungmook. Effects of intake and exhaust valve timing on combustion and emission characteristics of lean-burn direct-injection LPG engine[J]. Transactions of the KSME. B, 2015, 1(39): 45-51.

4. Can I, Oner C, Sugozu I. Experimental investigation of effect of stratified charging system adopted to gasoline engine running with LPG on engine performance[J]. Journal of the Energy Institute, 2013, 2(86): 113-118.

5. Pradeep V, Ramesh A. A novel twin injector strategy for direct cylinder barrel in jection of LPG in a $2 \mathrm{~S}-\mathrm{SI}$ engine[J]. Fuel, 2015, 162: 128-137.

6. C.D.Rakopoulos, A.M.Dimaratos, E.G.Giakoumis, et al. Evaluation of the effect of engine, load and turbocharger parameters on transient emissions of diesel engine[J]. Energy Conversion and Management, 2009, 50: 2381-2393.

7. Fu Jianqin. Continuous detecting on the operating and performance parameters of automotive engine under transient conditions and study of the heat-work conversion process[D]. Changsha:Hunan University, 2014.

8. Zhang Longping. Investigation of performance deterioration and control strategy of automotive diesel engine under transient operation conditions [D]. Changchun: Jilin University, 2015.

9. Zhang Longping, Liu Zhongchang, Tian Jing, et al. Investigation of the combustion deterioration of an automotive diesel engine under transient operation [J]. Science China Technological Sciences, 2014, 57(3): 480-488.

10. Heywood JB. Internal combustion engine fundamentals[M]. New York: McGrawHill, 1988.

11. Chen Gong. The analysis and test study on the influence of the engine combustion process to the exhaust temperature[D]. Harbin: Northeast Forestry University, 2013.

12. Wang Zhensuo, Deng Baoqing, Li Liguang, et al. Judgement of lean burn limit for SI engine using LPG[J].Journal of Jilin University (Engineering and Technology Edition), 2002, 32(04): 7-11. 